\title{
Radiographic Practices \& The Use of Apex Locators In Endodontic Treatment In Mumbai - A Comparison of Perceptions Between Endodontists \& Other Dental Practitioners.
}

\author{
Bhagwat Sumita A. Mds ${ }^{1,}$ Chalkar Aaditya Mds ${ }^{2}$ Padhye Leena V. Mds ${ }^{3}$ \\ ${ }^{1}$ Professor, Dept. Of Conservative Dentistry \& Endodontics, DYPU College Of Dentistry, Nerul, Navi Mumbai, \\ India. \\ ${ }^{2}$ Ex-Resident, Dept. Of Conservative Dentistry \& Endodontics, DYPU College Of Dentistry, Nerul, Navi \\ Mumbai, India. \\ ${ }^{3}$ Professor \& Head, Dept. Of Conservative Dentistry \& Endodontics, DYPU College Of Dentistry, Nerul, \\ Navi Mumbai, India. \\ Department And Institution: Dept. Of Conservative Dentistry \& Endodontics, DYPU College Of Dentistry, \\ Nerul, Navi Mumbai, India.
}

\begin{abstract}
:
Aims and Objective: The aim of our study was to assess the attitudes of general practitioners, endodontic specialists \& other specialists in and around Mumbai in relation to the use of electronic apex locator and the radiographic practices prevailing among them for root canal therapy.

Materials and Methods: A cross-sectional contact survey was conducted including 400 dental professionals in and around Mumbai who performed endodontic procedures. A specially prepared format exclusively designed for recording all the required relevant general information and information related to working length determination method was used as a tool for data collection.Data was tabulated in excel sheet and analyzed using SPSS 22.0 software.

Discussion and Conclusion:

From the survey, it was observed that the Endodontists employed apex locators and RVG more frequently than their colleagues' in general dental practice and this finding was statistically significant. It was also observed that there was a reticence amongst older practitioners to adopt more recent techniques. There is a very apparent deficit in the knowledge of potential benefits of using Electronic Apex Locators in routine endodontic treatment.
\end{abstract}

Keywords: Electronic Apex Locator, RVG, Survey.

\section{Introduction}

Working length determination is one of the critical steps that influence the successful outcome of rootcanal therapy. The cleaning, shaping \& obturation of the root canal cannot be accomplished accurately unless the working length is determined precisely. Traditional methods for establishing working length include the use of radiography ${ }^{1}$, anatomical averages and knowledge of anatomy, tactile sensation ${ }^{2}$ and moisture on a paper point. Each of these methods have limitations ${ }^{3,4}$ and do not allow precise localization of apical constriction and CDJ and do not guarantee that instrumentation beyond the apical foramen will be avoided ${ }^{5}$.

The use of conventional radiography remains the most common method of determining working length in Indian dental practices, though the use of Electronic apex locators is slowly becoming popular. But the absorption of their use into practice has not reflected enthusiastically. In our survey, we have assessed the attitudes of general practitioners, endodontic specialists \& other specialists in relation to the use of electronic apex locator and the radiographic practices prevailing among them for root canal therapy.

\section{Materials And Methods}

This cross-sectional contact survey included 400 dental professionals in and around Mumbai who routinely performed endodontic procedures. A specially prepared format exclusively designed for recording all the required relevant general information and information related to working length determination method was used as a tool for data collection (Appendix 1).Survey fundamentals: Guide to implement \& design survey were adhered to. ${ }^{6}$

The dental professionals were required to fill out the questionnaire consisting of questions with multiple choices. The questions were based on those asked in previous surveys developed in the $\mathrm{UK}^{1}$.Practitioners were asked to record information about their method of working length determination during endodontic procedures. Every individual who participated in the survey signed an informed consent form. 
Ethical clearance was obtained from the institutional ethical committee and permissions were obtained from the University Board of Clinical Studies.

The questionnaire was distributed to 410 dentists. 331 replies were received out of which 323 were complete and used for the study. A database was created for further analysis. Data description was carried out by frequency tables. When obtaining the numerical representation by percentages, the total number of answers for each query was taken into account. The Chi-square test was performed to check for significance of association.

\section{Results}

Table 1 shows the response percentages for each question in the questionaire.

\section{Dental professionals' profile.}

\section{Discussion}

The proportion of male Endodontists (46.6\%) and General Dental Practitioners (GDP) (47.8\%) were lower than the proportion of female Endodontists (53.4\%) and GDP (52.2\%).In other specialists, proportion of male $(51.9 \%)$ was higher than females $(48.1 \%)$. There was no significant association between Clinician and incidence of male /female ( $p>0.05)$. GDP group had a greater number of individuals less than 30 years of age, while the Endodontists and other specialists were of greater number in 31-49 age groups. There was significant association between Clinician and age of the respondent.

The majority of total respondents (57.83\%) graduated between 2005-2014. Maximum Endodontists (45.3\%) and other specialists (58.1\%) had finished their undergraduate training between 1995-2004. There was significant association between Clinician and year of graduation. Majority of Endodontists (54.0\%) and other specialists (55.2\%) completed their post-graduation in 2005-2014. There was no significant association between Clinician and year of post-graduation.

The majority of Endodontists (67.2\%) \& other specialist (68.6\%) reported working solely within private practice, and this was slightly higher than that of GDP (65\%). There was no significant association between Clinician and type of practice.Though, no significant association was found between the use of apex locator \& year of graduation, incidence percentage showed recent GDP and post graduates (after 1995) used Electronic Apex locators more often than older GDP and post graduates (before 1995).

\section{Radiographic practices.}

One of the main concerns in root canal treatment is to determine how far working instruments should be advanced within the root canal, and at what point the preparation and obturation should terminate ${ }^{7}$.

The root canal terminus is considered by many to be the $\mathrm{CDJ}^{8}$. In clinical practice, the minor apical foramen is a more consistent anatomical feature that can be regarded as being the narrowest portion of the canal system and thus the preferred landmark for the apical end-point for root canal treatment ${ }^{9}$.In our study, the majority of GDP (57.6\%) reported that they would retake the radiograph when the distance was 1-2 $\mathrm{mm}$ from radiographic apex. 47.6\% Endodontists and 58.4\% other specialists reported that they would retake the radiograph when the distance was $2-3 \mathrm{~mm}$ from radiographic apex. This difference was statistically significant.

With concerns over radiation exposure and the increased use of electronically stored patient records, several types of digital radiography machines have been introduced ${ }^{10}$ to clinical practice today.In our study, Endodontists used more Radiovisiography (RVG) (42.2\%) compared to GDP (27.5\%) and other specialists (32.2\%). Since $p$-value was less than 0.05 this indicatedthere was significant association between Clinician and use of RVG.However many studies have shown that canal lengths determined radiographically vary from actual root canal lengths by a considerable amount ${ }^{11,12}$. Although radiographs are a critical and an integral part of endodontic therapy ${ }^{13}$, there is an ongoing need to reduce exposure to ionizing radiation whenever possible. Figure 1-Graph 1 shows the use of RVG and radiographic films by the participants of the survey.

One of the most remarkable innovations in root canal treatment has been the development and production of electronic devices for detecting the canal terminus, thereby providing a method of reducing the number of radiographic exposures in root canal treatment by $85 \%{ }^{14}$. A number of researchers have stressed the benefits of combining both radiographic and electronic methods to optimize measurement accuracy. In 1918, Custer $^{15}$ was the first one to report the use of electric current to determine working length of a root canal. 
Because of the hazards of radiation, the technical problems associated with radiographic techniques and to avoid over-instrumentation beyond the canal terminus ${ }^{5}$, electronic working length determination has gained popularity amongst both general dentists and endodontists. Electronic apex locators reduce the number of radiographs required and assist where radiographic methods create difficulty. The development of the electronic apex locator has helped make the assessment of working length more accurate and predictable ${ }^{16}$.

90.85\% Endodontists and 88.5\% Other Specialists in our study used Electronic Apex locator for both single and multirooted teeth. This finding was statistically significant in comparison to GDP. Endodontist and other specialist practitioners use apex locator for both single and multirooted teeth while most of the GDP used it for multi rooted teeth(Figure 1, Graph 3).

$95.2 \%$ of Endodontists in our survey owned apex locators, while only $27.5 \%$ of GDP \& $31.9 \%$ of other specialist owned apex locators. $p$-value less than that of 0.05 indicated that there was a significant association between Clinician and use of Apex locator. In our survey, $90.8 \%$ of Endodontists used a combined technique of using both radiographs and electronic apex locator to determine working length which is also statistically significant amounts. Figure 1-Graph2 shows the frequency of possession of Electronic Apex Locators among the participants and Figure 1-Graph3 shows the use of Apex Locators among them. A reticence to use apex locators has also been reported within continental Europe with Bjørndal \& Reit $(2005){ }^{17}$ reporting that only $23 \%$ of Danish dentists used electronic apex locators (EALs) often with a further 19\% of respondents classified their use of apex locators as only occasional. Similar findings were observed within clinical practice in Belgium with $16 \%$ of dentists using EALs occasionally and a further $4.9 \%$ reporting seldom use ${ }^{18}$. In North America, $38.6 \%$ of Endodontists reported using EALs alone to determine working length with a further $52.5 \%$ using a radiographic examination, but only $8.9 \%$ of respondents reported using a combined technique ${ }^{19}$. The reason behind the reticence to routinely rely solely on the measurements derived from an apex locator appears to be multi-factorial. These include anatomical issues ${ }^{20}$, medico-legal implications ${ }^{19}$ and apex locator accuracy ${ }^{21}$. Endodontists and other specialists wanted to buy an apex locator but GDP responded most negatively in our survey as most felt radiograph was enough. This finding was statistically significant.

The present study found recently graduated GDPs and post graduates (after 1995) used apex locators more often than older GDPs and post graduates. Incidence percentage showed younger Endodontists and GDPs more likely to use an apex locator but the association was statistically not significant. This could be attributed to introduction of newer technologies in clinical practice of endodontics and in curriculum, which improved confidence in using new technologies. Maximum respondents in all groups were of the opinion that working length should be $0.5 \mathrm{~mm}$ short of the radiographic apex (Figure 1-Graph4).There was no significant difference between the three groups of respondents with regard to their views. Majority (79\%) of the respondents in all 3 groups agreed that the tactile sensation helped in judgment of working length. This finding was not statistically significant. Literature reveals substantial differences between European practices compared with treatment conducted in North America ${ }^{21}$. The European concept is to leave the root filling 1-2 mm short of the apex, whilst in North America clinical practice is to shape the canal to the 'radiographic apex terminus ${ }^{\text {,2 }}$. It was noticeable that $47.6 \%$ of Endodontists and $58.4 \%$ of other specialists in our survey reported taking a further radiograph when the difference between the end of the file and the radio-graphic apex was between 2 to $3 \mathrm{~mm}$ .The latter is in agreement with the current UK guidelines (Faculty of General Dental Practitioners 2004). Present study indicates a trend to follow the European practice of adopting the minor diameter as point of terminus of working length.

The present study highlighted significant differences between the uses of the preoperative radiograph by GDPs compared with Endodontists \& other specialists (Figure 2-Graph5). In the present study, we found that $66.3 \%$ of the GDPs, $81.1 \%$ of Endodontists \& $84.84 \%$ of other specialists took preoperative radiographs. This was lower than the results of Palmer et al. $(2009)^{23}$ where $98.5 \%$ of respondents reported using a preoperative film.Chandler \& Koshy (2002) also assessed the use of this radiographic examination by endodontic specialists, finding that a preoperative radiograph was always used by Endodontists, but the sample consisted of only five Endodontists $^{24}$. The latter was of limited relevance to the current study owing to the small sample size ${ }^{24}$. At $84.84 \%$, other specialists took maximum preoperative radiographs while $83.3 \%$ Endodontists took maximum working length and $86.67 \%$ Endodontists took master cone radiograph. Incidence of immediate postoperative radiographs was low in all 3 groups with $41.13 \%$ GDP, $36.67 \%$ Endodontists and $32.33 \%$ other specialists.

Electronic apex locators (EALs) can accurately determine the location of root perforations, making them significantly more reliable than radiographs after root instrumentation. Readings that are significantly shorter than the original working length can be an indication of perforation ${ }^{25}$. $8.5 \%$ GDP and $54.5 \%$ other specialist relied on radiographs, while majority of Endodontists (58.6\%) followed combined approach of electronic apex locator and radiograph for detection of perforation (Figure 2-Graph6). Endodontic specialists use Apex locator as well as radiograph while most of GDP and other specialists used only radiograph. This is mainly due to increased use of electronic apex locator by Endodontists as compared to GDPs who rely on traditional radiographic methods. There also may be lacunae in the training of GDPs and other specialists at the undergraduate level with regards to use of EAL in handling cases of perforation. 
50.0\% GDP and 57.9\% other specialists did follow up for 15 days while maximum Endodontists $(32.5 \%)$ did follow up for 6 months. This result was not statistically significant.

\section{Conclusions}

Number of female Endodontists was more than number of male Endodontists. Young GDPs were in greater number compared to other groups. Majority of Endodontists finished their post-graduation after 2004. Use of RVG was more by Endodontists and also, majority of them owned electronic apex locator. Young practitioners, who graduated after 1995, were more likely to use an apex locator. Majority of clinicians were of opinion of keeping working length short $0.5 \mathrm{~mm}$ of apex (Figure 1-Graph4). Maximum other specialists took preoperative radiograph, while maximum Endodontists took working length and master cone radiograph. Overall rate of follow up of treated patients was found to be low; which is not a good practice.

From the survey, it was observed that the Endodontists employed apex locators and RVG more frequently than their colleagues in general dental practice. It was also observed that there was a reticence amongst older practitioners to adopt more recent techniques. There is a very apparent deficit in the knowledge of potential benefits of using Electronic Apex Locators in routine endodontic treatment.

\section{References}

[1]. Stein TJ, Corcoran JF. Radiographic "working length" revisited. Oral Surg Oral Med Oral Pathol. 1992 Dec; 74(6):796-800

[2]. Chandler N, Bloxham G. The influence of two handle designs and gloves on the performance of a simulated endodontic task. J Endod. 1990 Nov; 16(11):541-2.

[3]. Tamse A, Kaffe I, Fishel D. Zygomatic arch interference with correct radiographic diagnosis in maxillary molar endodontics. Oral Surg Oral Med Oral Pathol. 1980 Dec; 50(6):563-6.

[4]. John D. West. What is required to generate consistently 3-D obturated root canal systems? Dentistry today 2012 jan: 14

[5]. ElAyouti A, Weiger R, Löst C. Frequency of overinstrumentation with an acceptable radiographic working length. J Endod. 2001 Jan; 27(1):49-52.

[6]. Nancy Thayer-Hart 'Survey Fundamentals: A Guide to Designing and Implementing Surveys', Version 2. The University of Wisconsin System Board of Regents, December 2010.

[7]. Schilder H Filling root canals in three dimensions. Dent Clin North Am 1967, 11:723-44.

[8]. John I. Ingle, Leif K. Bakland, J. Craig Baumgartner,Textbook of Endodontics Sixth Edition.

[9]. M. H. Nekoofar, M. M. Ghandi, S. J. Hayes \& P. M. H. Dummer. The fundamental operating principles of electronic root canal length measurement devices. Int Endod J. 2006 Aug; 39(8):595-609.

[10]. M. P. J. Gordon \& N. P. Chandler Electronic apex locators. Int Endod J, 37, 425-437, 2004.

[11]. Martínez-Lozano MA, Forner-Navarro L, Sánchez-Cortés JL, Llena-Puy C. Methodological considerations in the determination of working length. Int Endod J. 2001 Jul; 34(5):371-6.

[12]. Endodontic Topics Volume 10, Issue 1, pages 3-29, March 2005

[13]. Dummer PM, McGinn JH, Rees DG. The position and topography of the apical canal constriction and apical foramen. Int Endod J. 1984 Oct; 17(4):192-8

[14]. Vaishali Parekh,Chirag Taluja.Comparative study of periapical of radiographic techniques for apex locator for endodontic working length estimation: An ex-Vivo study. J Contemp Dent Pract 2011;12(2):131-134.

[15]. Palmer NO, Ahmed M, and Grieveson B. Summary of: An investigation of current endodontic practice and training needs in primary care in the north west of England. Br Dent J. 2009 Jun 13;206(11):E22.

[16]. Sonal Sui,Sumit Mohan,Vineet Vinayak,Prabhjyot Kaur. Electronic Apex Locators.Journal of oral sciences \& oral Rehabilitation jan-March2013.

[17]. Bjørndal L, Reit C. The adoption of new endodontic technology amongst Danish general dental practitioners. Int Endod J. 2005 Jan; 38(1):52-8.

[18]. Hommez GM, Braem M, De Moor RJ. Root canal treatment performed by Flemish dentists. Part 1. Cleaning and shaping. Int Endod J. 2003 Mar; 36(3):166-73.

[19]. Lee M, Winkler J, Hartwell G, Stewart J, Caine R. Current trends in endodontic practice: emergency treatments and technological armamentarium. J Endod. 2009 Jan; 35(1):35-9. doi: 10.1016/j.joen.2008.10.007.

[20]. S.Kim Modern Endodontic Practice Dent Clin North Am. 2004 Jan; 48

[21]. I. Orafi \& V. E. Rushton The use of radiography and the apex locator inendodontic treatment within the UK: a comparison between endodontic specialists and general dental practitioners. Int Endod J. 2013 Apr; 46(4):355-64.

[22]. Simon S, Machtou P, Adams N, Tomson P, Lumley P. Apical Limit and Working Length in Endodontic . Dent Update. 2009 Apr;36(3):146-50, 153.

[23]. Palmer NO, Ahmed M, and Grieveson B. Summary of: An investigation of current endodontic practice and training needs in primary care in the north west of England. Br Dent J. 2009 Jun 13;206(11):E22.

[24]. NP Chandler and S Koshy Radiographic practices of dentists undertaking endodontics in New Zealand. Dentomaxillofac Radiol. 2002 Sep; 31(5):317-21.

25. Igor Tsesis \& Zvi Fuss Diagnosis and treatment of accidental root perforations. Endodontic Topics 2006, 13, 95-107 
Radiographic Practices \& The Use Of Apex Locators In Endodontic Treatment In Mumbai...
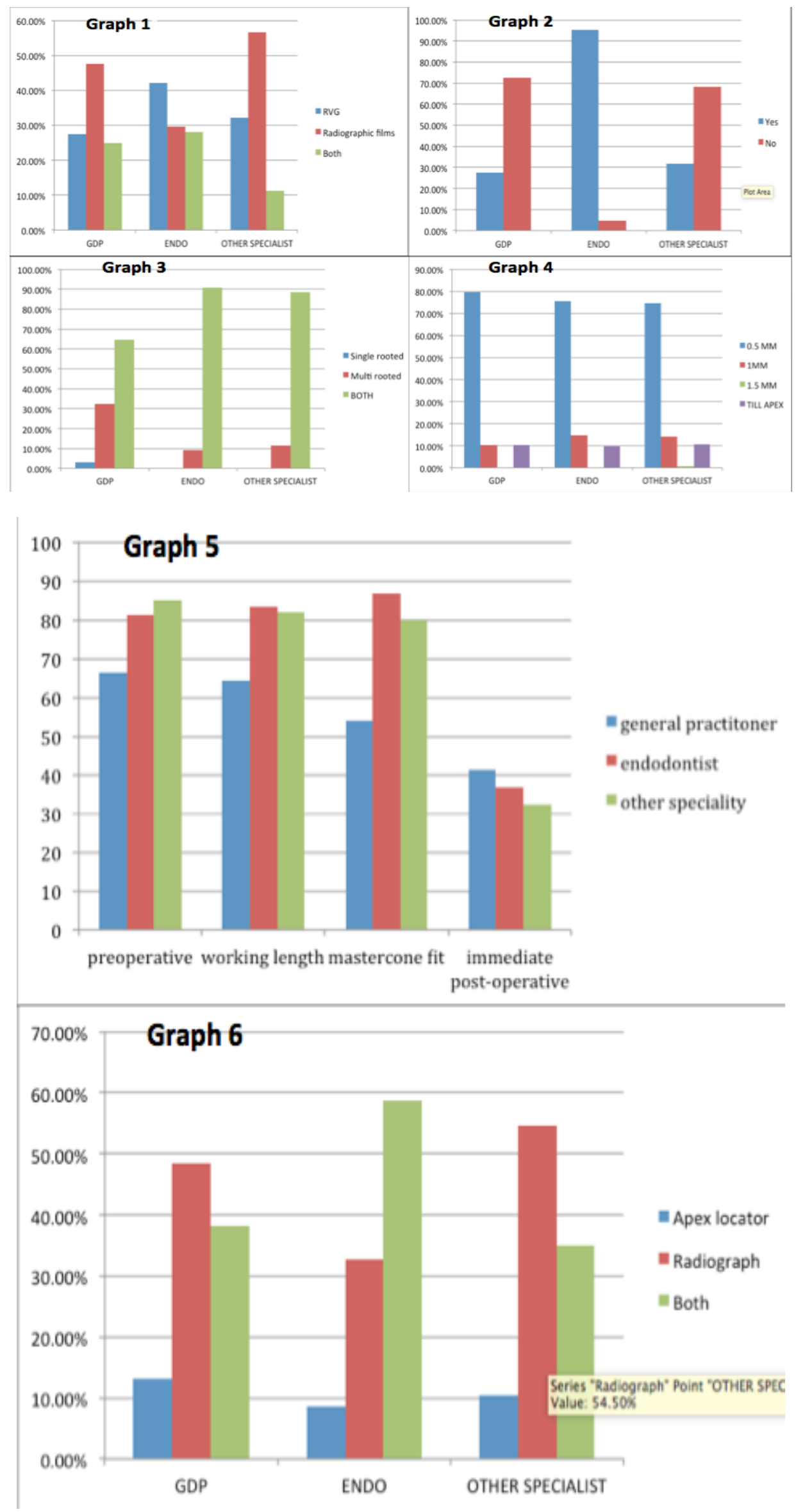
Radiographic Practices \& The Use Of Apex Locators In Endodontic Treatment In Mumbai...

\begin{tabular}{|c|c|c|c|c|}
\hline $\begin{array}{l}\text { S. } \\
\text { No. }\end{array}$ & Questions asked in the questionnaire. & $\begin{array}{l}\text { General } \\
\text { Dental } \\
\text { Practitioner }\end{array}$ & Endedontiat & $\begin{array}{l}\text { Other } \\
\text { specialist }\end{array}$ \\
\hline \multirow[t]{2}{*}{1} & \multirow{2}{*}{ Profile of the respondents :- male } & $47.8 \%$ & $46.6 \%$ & $51.9 \%$ \\
\hline & & $52.2 \%$ & $53.4 \%$ & $48.1 \%$ \\
\hline \multirow[t]{3}{*}{2} & \multirow{3}{*}{$\begin{array}{l}\text { Age of respondents:-less than } 30 \\
31-50 \\
\text { More than } 50\end{array}$} & $53.4 \%$ & $34.4 \%$ & $35.8 \%$ \\
\hline & & $46.6 \%$ & $55.7 \%$ & $54.99 \%$ \\
\hline & & 0 & $9.8 \%$ & $9.2 \%$ \\
\hline \multirow[t]{2}{*}{3} & \multirow{2}{*}{$\begin{array}{l}\text { Type of practice :-Alone } \\
\text { With other dentist }\end{array}$} & $65.0 \%$ & $67.2 \%$ & $68.6 \%$ \\
\hline & & $35.0 \%$ & $32.9 \%$ & $31.4 \%$ \\
\hline \multirow[t]{3}{*}{4} & \multirow[t]{3}{*}{ Use of RVG :- RVG } & $27.5 \%$ & $42.2 \%$ & $32.2 \%$ \\
\hline & & $47.5 \%$ & $29.7 \%$ & $56.5 \%$ \\
\hline & & $25.0 \%$ & $28.1 \%$ & $11.3 \%$ \\
\hline \multirow[t]{4}{*}{5} & \multirow{4}{*}{ Limit for radiographic repeats } & $57.6 \%$ & $15.9 \%$ & $12.7 \%$ \\
\hline & & $31.8 \%$ & $47.6 \%$ & $58.4 \%$ \\
\hline & & $10.6 \%$ & $30.2 \%$ & $27.7 \%$ \\
\hline & & 0 & $6.3 \%$ & $1.2 \%$ \\
\hline \multirow[t]{2}{*}{6} & \multirow{2}{*}{$\begin{array}{l}\text { Possession of Electronic Apex Locator. } \quad \text { Yes } \\
\text { No }\end{array}$} & $27.5 \%$ & $95.2 \%$ & $31.9 \%$ \\
\hline & & $72.5 \%$ & $4.8 \%$ & $68.1 \%$ \\
\hline \multirow[t]{3}{*}{7} & \multirow{3}{*}{$\begin{array}{l}\text { Use of Apex Locator: Single rooted } \\
\qquad \begin{array}{c}\text { Multi rooted } \\
\text { Both }\end{array}\end{array}$} & $3.2 \%$ & 0 & 0 \\
\hline & & $32.3 \%$ & $9.2 \%$ & $11.5 \%$ \\
\hline & & $64.5 \%$ & $90.8 \%$ & $88.5 \%$ \\
\hline \multirow[t]{2}{*}{8} & \multirow{2}{*}{$\begin{array}{l}\text { Opinion about Apex locators. :- Yes, want to buy } \\
\text { No, radiographs }\end{array}$} & $88.1 \%$ & 100 & $96.9 \%$ \\
\hline & & $11.9 \%$ & 0 & $3.1 \%$ \\
\hline \multirow[t]{4}{*}{9} & \multirow{4}{*}{$\begin{aligned} \text { Association with age (use of apex locator in all cases } \\
\text { i. anterior \& posterior teeth) :- } \\
$\[ \begin{aligned} \text { less than } 30 \\
30-50 \\
\text { More than } 50\end{aligned} \]$\end{aligned}$} & & & \\
\hline & & $58.8 \%$ & $40.9 \%$ & $50.7 \%$ \\
\hline & & $41.2 \%$ & $45.5 \%$ & $46.3 \%$ \\
\hline & & 0 & $13.6 \%$ & $3 \%$ \\
\hline \multirow[t]{5}{*}{10} & \multirow{5}{*}{ 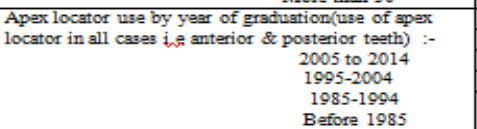 } & & & \\
\hline & & $50.0 \%$ & $37.0 \%$ & $40.6 \%$ \\
\hline & & $45.0 \%$ & $43.0 \%$ & $55.1 \%$ \\
\hline & & $5.0 \%$ & $15.2 \%$ & $2.99 \%$ \\
\hline & & 0 & $4.3 \%$ & $1.4 \%$ \\
\hline \multirow[t]{5}{*}{11} & Apical limit for BMP & & & \\
\hline & $0.5 \mathrm{~mm}$ fom apex & $79.5 \%$ & $75.4 \%$ & $74.6 \%$ \\
\hline & $1 \mathrm{~mm}$ from spex & $10.3 \%$ & $14.8 \%$ & $14.1 \%$ \\
\hline & $1.5 \mathrm{~mm}$ from apex & 0 & & $0.6 \%$ \\
\hline & Till apex & $10.3 \%$ & $9.8 \%$ & $10.7 \%$ \\
\hline 12 & Tactile sensation & & & \\
\hline & Yes & $78.4 \%$ & $80.6 \%$ & $78.4 \%$ \\
\hline & No & $21.6 \%$ & $19.4 \%$ & $21.6 \%$ \\
\hline 13 & Use of radiograph in various stages & & & \\
\hline & $\begin{array}{l}\text { PREOPERATTVE } \\
\text { WORKDNG LENGTH }\end{array}$ & $\frac{66.3 \%}{64.42 \%}$ & $\frac{81.1 \%}{83.3 \%}$ & $\frac{84.84 \%}{81.81 \%}$ \\
\hline & $\begin{array}{l}\text { MASTERCONE FIT } \\
\text { MARRIA }\end{array}$ & $53.84 \%$ & $86.67 \%$ & $79.8 \%$ \\
\hline & IMIMEDIATE POSTOPERATTVE & $41.13 \%$ & $36.67 \%$ & $32.33 \%$ \\
\hline 14 & Detection of perforation & & & \\
\hline & Apex locator & $13.2 \%$ & $8.6 \%$ & $10.4 \%$ \\
\hline & Radiograph & $48.5 \%$ & $32.8 \%$ & $54.5 \%$ \\
\hline & Both & $38.2 \%$ & $52.6 \%$ & $35.1 \%$ \\
\hline 15 & Follow up & & & \\
\hline & 15 dsys & $\frac{50.0 \%}{19.2 \%}$ & $\frac{25.3 \%}{25 \%}$ & $\frac{57.9 \%}{21.3 \%}$ \\
\hline & 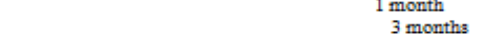 & $\begin{array}{l}19.2 \% \\
12.8 \%\end{array}$ & $\frac{25 \%}{17.2 \%}$ & $\frac{21.3 \%}{15.2 \%}$ \\
\hline & 6 months & $17.9 \%$ & $32.5 \%$ & $5.6 \%$ \\
\hline
\end{tabular}

